\title{
Development of Refractive Error and Strabismus in Children with Down Syndrome
}

\author{
Mary Cregg, ${ }^{1}$ J. Margaret Woodbouse, ${ }^{1}$ Ruth E. Stewart, ${ }^{1}$ Valerie H. Pakeman, ${ }^{1}$ \\ Nathan R. Brombam, ${ }^{1}$ Helen L. Gunter, ${ }^{1}$ Lidia Trojanowska, ${ }^{1}$ Margaret Parker, ${ }^{1}$ and \\ William I. Fraser ${ }^{2}$
}

Purpose. To investigate the development of refractive errors and strabismus in a cohort of children with Down syndrome.

MethoD. Data for 55 children with Down syndrome who are participating in this longitudinal study of visual development, first examined by us when aged less than 2 years and on at least two other occasions, were analyzed. Mohindra retinoscopy was used to measure refractive error. Ocular alignment was assessed using the Hirschberg test and, when possible, the cover test.

Results. Despite the high prevalence of large refractive errors in children with Down syndrome, longitudinal data showed that these are not always present in early infancy. Twenty-one (38\%) of the children were emmetropic throughout the study. Of the 24 children with a significant refractive error at the outset, only 6 (25\%) showed emmetropization. The others retained or increased their refractive errors. The remaining 10 children were emmetropic at the outset, but then had a significant refractive error develop. There is a high prevalence of strabismus in children with Down syndrome (29\% of the total group), which cannot be attributed to the presence of hypermetropia or anisometropia.

Conclusions. The retention or development of infantile refractive errors in many children with Down syndrome indicates a failure of emmetropization. All children were at risk of strabismus whatever the refractive error. The findings have implications for timing of screening programs. (Invest Ophthalmol Vis Sci. 2003;44:1023-1030) DOI:10.1167/iovs.01-0131

$S^{\text {tis }}$ tudies of refraction in normally developing infants confirm that most are hypermetropic. The degree of hypermetropia decreases with increasing age, with the most rapid decrease occurring in the first 12 months of life. ${ }^{1-4}$ The decrease in ametropia toward emmetropia in early childhood is termed emmetropization. Both Saunders et al. ${ }^{2}$ and Atkinson et al. ${ }^{5}$ have shown that in normal emmetropizing eyes, the greater the initial hypermetropia, the greater the rate of decrease. Children

From the ${ }^{1}$ Department of Optometry and Vision Sciences, Cardiff University, Cardiff, Wales, United Kingdom; and the ${ }^{2}$ Welsh Centre for Learning Disabilities, University of Wales College of Medicine, Cardiff, Wales, United Kingdom.

Supported by grants from the Medical Research Council (MC, HLG); PPP Healthcare (RES, LT); the Community Fund in collaboration with Mencap (NRB); and the Down's Syndrome Association, United Kingdom (VHP, MP).

Submitted for publication January 31, 2001; revised May 3, July 9 , and September 4, 2002; accepted July 11, 2002.

Commercial relationships policy: $\mathrm{N}$.

The publication costs of this article were defrayed in part by page charge payment. This article must therefore be marked "advertisement" in accordance with 18 U.S.C. $\$ 1734$ solely to indicate this fact.

Corresponding author: J. Margaret Woodhouse, Department of Optometry \& Vision Sciences, Cardiff University, Redwood Building, King Edward VII Avenue, Cardiff CF10 3NB, UK;

woodhouse@cardiff.ac.uk. become more emmetropic or even slightly myopic as they get older. $^{6-8}$ Gwiazda et al. ${ }^{9}$ reported that $80 \%$ of 6 -year-olds were emmetropic (i.e., mean sphere between 0.00 and $0.49 \mathrm{D}$ ). Similarly, myopia and astigmatism in normally developing children decrease in the first 4 years of life..$^{3,10-13}$ Recent longitudinal studies have confirmed the presence of an emmetropization process in individual children..$^{2,4,9,13}$ Troilo $^{14}$ and Wildsoet $^{15}$ have provided comprehensive reviews of the literature on emmetropization.

High hypermetropia at the age of 1 year is associated with a risk of developing strabismus. ${ }^{10,15-18}$ Abrahamsson et al. ${ }^{18}$ found that before the onset of strabismus, a decrease in refractive error was never seen in the eye that later became the deviating eye. Thus, a failure of emmetropization rather than the magnitude of the initial refractive error may be implicated in the development of strabismus.

Among children and adults with Down syndrome, refractive errors tend to be far greater than among the normal population. ${ }^{19-22}$ Although there is a popular misconception that most individuals with Down syndrome are myopic, in fact hypermetropia is much more common. ${ }^{19-21}$ However, reports show that although hypermetropia is more common, in individuals with myopia the degree of myopia can be extremely high. ${ }^{19,20,23}$

Previous work by our group has shown that mean refractive error does not differ between normal children and children with Down syndrome and that the range of errors in early infancy is similar in the two groups. However, the range of refractive errors in children with Down syndrome increases with age. ${ }^{19}$ A recent longitudinal study by Haugen et al. ${ }^{24}$ reported, from cycloplegic refraction data, that far fewer children show a reduction in refractive error over time than would be expected in a developmentally normal population. ${ }^{24}$ of their group of 54 young children with Down syndrome, 18 had emmetropia or low hypermetropia (spherical equivalent +2.00 $\mathrm{D}$ or less) and maintained the refractive state, 5 had a decrease in hypermetropia (by $1.50 \mathrm{D}$ or more), 16 maintained significant hypermetropia $(+2.25 \mathrm{D}$ or more), 11 had increasing hypermetropia (by $1.50 \mathrm{D}$ or more), and 4 had myopia $(<0.00$ D). Six more children were excluded from analysis because of anisometropia $(>1.00$ in spherical power or $>1.50$ in cylinder). Haugen et al. also reported that astigmatism in their children did not diminish in the expected way. Nine of the 34 subjects with astigmatism at the last visit had oblique axes and the investigators commented on the consistency of axes, with right eyes displaying axes (of the negative cylinder) in the $135^{\circ}$ meridian and left eyes displaying axes in the $45^{\circ}$ meridian. Overall, their data are suggestive of a failure in emmetropization.

In the current study, we recorded data from noncycloplegic refractions of our cohort of children with Down syndrome, conducted a more extensive analysis of changes in refractive error, and investigated any relationship between refraction and strabismus. 


\section{Methods}

\section{Subjects}

Ninety-eight children with Down syndrome are participating in our longitudinal study of visual development. The recruitment protocol is outlined in a separate publication. ${ }^{25}$ The youngest children to enter the cohort were 2 to 3 months of age. Others were older at the outset of the study in 1992 and 1993. For the present analysis, we selected all the children in the study who were first examined at less than 2 years of age and on at least two more occasions when examiner confidence was high for refractive measures; 55 children fulfilled these criteria. Because refractive error changes most rapidly in the first year of life, children were divided into an infant group, those first examined under the age of 12 months $(n=31)$, and an older group, those first examined between the ages of 12 and 24 months $(n=24)$. At the first visit for the infant group, ages ranged from 1.9 to 10.7 months (mean age, $5.6 \pm 2.8[\mathrm{SD}])$. Among the children in the older group, age at first visit ranged from 12.0 to 22.3 months (mean age, $16.5 \pm 3.2$ ). Experimental protocols were conducted in compliance with the Declaration of Helsinki and were approved by local ethical research committees in the areas of residence of the children.

\section{Procedure}

Thirty-eight of the children were assessed at home, and 12 of these children were assessed at the later visits at school (with a parent or classroom aide always present). These children were taking part in a longitudinal study incorporating cognitive tests, and therefore home and school visits had two advantages. First, children with Down syndrome have a poor attention span. ${ }^{26}$ Home and school assessments present minimal distractions, and the child is more likely to cooperate with the cognitive tests. Second, parents of children who lived at a location distant from the university department may otherwise have been unable or unwilling to travel to participate in the study. Seventeen children were examined at the Cardiff University Eye Clinic. In all cases, refractive error was assessed objectively with Mohindra retinoscopy. ${ }^{27}$ The study protocol did not include the use of cycloplegic agents, because a longitudinal study necessitates repeated assessments, and many parents would have been less likely to participate if eye drops had been used. ${ }^{28}$ The Mohindra technique has been shown to be equivalent to cycloplegic retinoscopy in both normally developing children and children with Down syndrome. ${ }^{19,29,30}$ In our earlier study comparing cycloplegic and Mohindra retinoscopy in children with Down syndrome, ${ }^{19}$ we assessed 14 children aged less than 12 months and found no significant differences in the results obtained by the techniques. All those children are included in the present study. Mohindra retinoscopy was performed in darkness, with a dimmed retinoscope beam. In the home or school environment, darkness was achieved either by blacking out windows in a small room or by the use of a light-proof portable playhouse. For a working distance of $50 \mathrm{~cm}$, a compensation of $0.75 \mathrm{D}$ was made for infants aged 2 years and less and of $1.00 \mathrm{D}$ for children more than 2 years of age. ${ }^{30}$ Four of the authors (MC, JMW, RES, VHP) performed the refractions. All are qualified optometrists, and all had experience with assessing children with learning disabilities before involvement in the study. In the majority $(>95 \%)$ of cases, records of previous refractions were not consulted before retinoscopy was performed. Only when there were parental concerns and the optometrist made a clinical judgment to consult records was the previous refraction known. Ocular alignment was assessed with the Hirschberg test, and, when the child was able to cooperate, with the cover test. The child fixated a penlight, and strabismus was recorded when the corneal reflection in one eye was clearly positioned more temporally (esodeviation) or more nasally (exodeviation) than the other. The minimum misalignment of the corneal reflection readily visible by this technique is approximately 0.5 $\mathrm{mm}$, corresponding to a strabismus of $4^{\circ}$ to $5^{\circ}$. With the cover test, strabismus was recorded if there was a repeatable movement of the noncovered eye to take up fixation. The minimum deviation visible

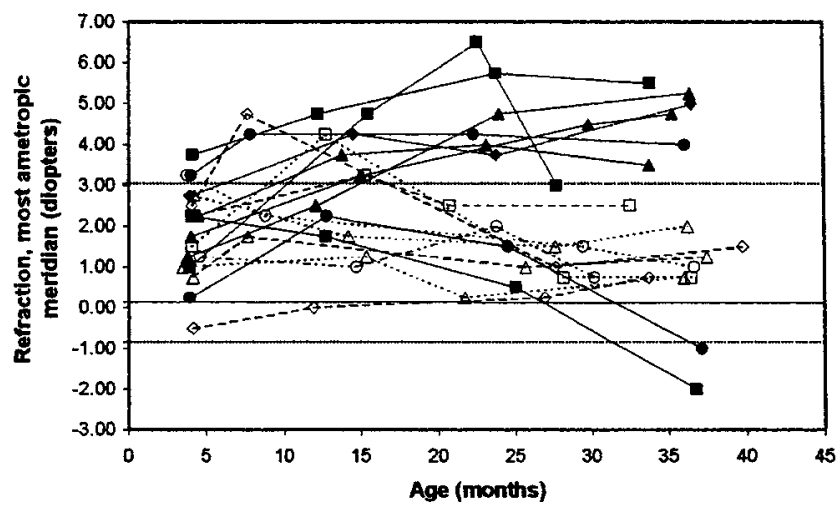

FIGURE 1. Longitudinal progression of refractive error in 18 children with Down syndrome examined at similar ages. Horizontal dashed lines: limits of emmetropia (less than +3.00 or more than $-1.00 \mathrm{D}$ ). Filled symbols: children whose refractive error increased by more than $0.75 \mathrm{D}$ between first and last visits and/or was significant at the last visit.

with this test is approximately $2^{\circ}$ to $3^{\circ}$, but this would be possible only with a very cooperative child and steady fixation. Strabismus was recorded for the visit only if the examiner was confident in obtaining a repeatable result and a child was classified as strabismic for the purposes of analysis, only if strabismus was recorded on two or more visits. Thus, in cases of doubt, the data here underestimate the prevalence of strabismus.

\section{Results}

Although refractive error was assessed on each occasion in both eyes of every child, the refractive error presented herein is the most ametropic meridian of the right eye, except in cases of strabismus in which the left eye was the fixing eye. In these cases, the most ametropic meridian of the left eye was used for analysis. This was so, even when strabismus developed during the course of the study (i.e., data were retrospectively chosen for the fixing eye). The type of ametropia was classified according to whether it could be considered clinically significant using definitions in line with previous studies. ${ }^{16,31}$ Myopes were defined as those children with the most ametropic meridian of $-1.00 \mathrm{D}$ or less, hypermetropes as those with the most ametropic meridian of $+3.00 \mathrm{D}$ or greater; the remainder were considered emmetropes. Significant astigmatism was defined as $1.00 \mathrm{D}$ or greater. ${ }^{12,19,32-34}$ Significant anisometropia was defined as a difference of $1.50 \mathrm{D}$ or more between the corresponding meridians of a pair of eyes. ${ }^{35,36}$

\section{Longitudinal Changes in Refractive Error}

Although every attempt was made to visit children at similar ages, it proved difficult. Repeated-measures analysis of longitudinal results could therefore be conducted only with a subset of the data. Eighteen children were examined regularly from the age of 3 months, and refraction data for each of these children were available at approximately the following ages: 4 , 12,24 , and 36 months. Mean refractions were $+1.85 \pm 1.13$, $+2.88 \pm 1.46,+2.57 \pm 1.99,+2.26 \pm 2.13 \mathrm{D}$ at those ages, and the refractions did not vary between the first and final visits $(t=0.747, P=0.466)$. The variance, however, shows a significant increase with age (the Levene statistic $=4.09, P=$ 0.01 ). Figure 1 shows individual data for these children. Because both the interexaminer and intraexaminer repeatability of Mohindra retinoscopy is $\pm 0.75 \mathrm{D},{ }^{30}$ a change in refractive error was defined as a difference greater than $0.75 \mathrm{D}$ between the first and last visits. Data for children whose refractive errors 
TABLE 1. Refractive Error Data and Refractive Error Grouping of Children with Down Syndrome Who Were First Examined before the Age of 12 Months

First Visit

\begin{tabular}{|c|c|c|c|c|c|c|c|c|c|c|c|c|c|c|c|c|}
\hline Child & Age & Rsph & Rcyl & Raxis & Lsph & Lcyl & Laxis & Group & Age & Rsph & Rcyl & Raxis & Lsph & Lcyl & Laxis & Group \\
\hline $\mathrm{SP}^{*}$ & 8.0 & +5.75 & 1.00 & 90 & +5.75 & 1.00 & 90 & $\mathrm{H}$ & 35.0 & +8.00 & 0.50 & 90 & +8.25 & 0.50 & 90 & $\mathrm{H}$ \\
\hline $\mathrm{RH}$ & 8.9 & +5.25 & 1.50 & 90 & +4.75 & 1.50 & 90 & $\mathrm{H}$ & 33.9 & +3.50 & 0.00 & & +3.50 & 0.00 & & $\mathrm{H}$ \\
\hline VG & 10.7 & +4.50 & 0.50 & 90 & +4.50 & 0.50 & 90 & $\mathrm{H}$ & 27.6 & +6.00 & 0.75 & 90 & +6.00 & 0.75 & 90 & $\mathrm{H}$ \\
\hline $\mathrm{TH}^{*}$ & 10.3 & +3.75 & 0.75 & 180 & +3.75 & 0.75 & 180 & $\mathrm{H}$ & 21.4 & +4.25 & 0.50 & 180 & +4.25 & 0.00 & & $\mathrm{H}$ \\
\hline EM & 2.8 & +3.25 & 0.00 & & +2.25 & 0.00 & & $\mathrm{H}$ & 48.1 & +5.00 & 0.00 & & +5.00 & 0.00 & & $\mathrm{H}$ \\
\hline $\mathrm{DH}$ & 4.0 & +2.75 & 0.50 & 90 & +3.00 & 0.50 & 90 & $\mathrm{H}$ & 42.3 & +3.00 & 0.00 & & +3.00 & 0.00 & & $\mathrm{H}$ \\
\hline $\mathrm{CC}^{*}$ & 3.8 & +2.25 & 1.00 & 90 & +1.25 & +2.00 & 90 & $\mathrm{H}$ & 36.6 & +1.00 & 0.00 & & +1.00 & 0.00 & & $\mathrm{E}$ \\
\hline HM & 9.7 & +2.50 & 0.50 & 90 & +2.75 & 0.50 & 90 & $\mathrm{H}$ & 36.6 & +2.00 & 1.00 & 175 & +2.00 & 0.00 & & $\mathrm{H}$ \\
\hline $\mathrm{NB}^{*}$ & 3.0 & +2.75 & 0.00 & & +2.75 & 0.00 & & $\mathrm{E}$ & 42.3 & +4.50 & 0.00 & & +4.50 & 0.00 & & $\mathrm{H}$ \\
\hline $\mathrm{DP}$ & 2.9 & +2.25 & 0.00 & & +2.25 & 0.00 & & $\mathrm{E}$ & 36.8 & -2.00 & 1.50 & 70 & -1.00 & 1.00 & 110 & M \\
\hline JP1 & 5.7 & +2.25 & 0.00 & & +2.25 & 0.00 & & $\mathrm{E}$ & 30.3 & +1.00 & 0.50 & 180 & +1.00 & 0.00 & & $\mathrm{E}$ \\
\hline DO & 3.6 & +2.00 & 0.00 & & +2.00 & 0.00 & & $\mathrm{E}$ & 48.4 & +1.50 & 0.00 & & +1.50 & 0.00 & & $\mathrm{E}$ \\
\hline MD & 9.6 & +1.75 & 0.75 & 90 & +2.75 & 0.50 & 90 & $\mathrm{E}$ & 18.6 & +3.25 & 0.00 & & +3.25 & 0.50 & 180 & $\mathrm{H}$ \\
\hline $\mathrm{RD}$ & 4.5 & +1.75 & 0.50 & 90 & +2.75 & 0.00 & & $\mathrm{E}$ & 33.8 & +3.50 & 0.00 & & +3.50 & 0.50 & 90 & $\mathrm{H}$ \\
\hline $\mathrm{CM}^{*}$ & 4.0 & +1.25 & 0.00 & & +1.75 & 0.00 & & $\mathrm{E}$ & 44.8 & +6.00 & 0.25 & 90 & +6.00 & 0.25 & 90 & $\mathrm{H}$ \\
\hline MT & 9.0 & +1.50 & 0.00 & & +1.50 & 0.00 & & $\mathrm{E}$ & 27.1 & -5.00 & 0.50 & 180 & -3.75 & 0.50 & 90 & M \\
\hline $\mathrm{VL}^{*}$ & 8.9 & +1.75 & 0.75 & 180 & +1.50 & 0.00 & & $\mathrm{E}$ & 18.5 & +3.75 & 0.50 & 180 & +3.75 & 0.50 & 180 & $\mathrm{H}$ \\
\hline $\mathrm{JH}$ & 2.9 & +1.25 & 0.00 & & +1.00 & 0.25 & 180 & $\mathrm{E}$ & 49.4 & +1.50 & 0.50 & 90 & +1.75 & 0.25 & 90 & $\mathrm{E}$ \\
\hline SR & 4.6 & +1.25 & 0.00 & & +1.25 & 0.00 & & $\mathrm{E}$ & 43.3 & +0.25 & 0.75 & 90 & +0.25 & 0.75 & 90 & $\mathrm{E}$ \\
\hline $\mathrm{CW}^{*}$ & 3.8 & +1.25 & 0.00 & & +1.25 & 0.00 & & $\mathrm{E}$ & 36.4 & +4.75 & 0.50 & 180 & +4.75 & 0.50 & 180 & $\mathrm{H}$ \\
\hline DS & 4.2 & +0.25 & 2.00 & 90 & -1.25 & 1.50 & 90 & $\mathrm{E}$ & 32.6 & +1.50 & 1.00 & 180 & +1.50 & 1.00 & 180 & $\mathrm{E}$ \\
\hline MB & 3.5 & +0.50 & 0.50 & 90 & +0.75 & 0.50 & 90 & $\mathrm{E}$ & 40.0 & +2.00 & 0.25 & 90 & +2.25 & 0.50 & 90 & $\mathrm{E}$ \\
\hline $\mathrm{LL}^{*}$ & 9 & -0.25 & 2.00 & 90 & +0.25 & 1.00 & 160 & $\mathrm{E}$ & 31.2 & +1.50 & 0.50 & 90 & +1.50 & 0.50 & 90 & $\mathrm{E}$ \\
\hline KW & 9.2 & +0.50 & 0.00 & & +0.50 & 0.00 & & $\mathrm{E}$ & 30.5 & +1.25 & 0.00 & & +1.25 & 0.00 & & $\mathrm{E}$ \\
\hline $\mathrm{JR}^{*}$ & 3.0 & -0.25 & 1.00 & 150 & +0.75 & 0.50 & 150 & $\mathrm{E}$ & 43.3 & +1.75 & 0.50 & 90 & +1.75 & 0.75 & 90 & $\mathrm{E}$ \\
\hline GJ & 2.8 & +0.25 & 0.00 & & +0.25 & 0.00 & & $\mathrm{E}$ & 42.4 & +0.50 & 0.00 & & +0.50 & 0.00 & & $\mathrm{E}$ \\
\hline $\mathrm{AJ}$ & 2.7 & 0.00 & 0.00 & & 0.00 & 0.00 & & $\mathrm{E}$ & 50.3 & +0.75 & 0.00 & & +0.75 & 0.00 & & $\mathrm{E}$ \\
\hline $\mathrm{JF}^{*}$ & 3.9 & +0.25 & 0.00 & & +0.25 & 1.00 & 90 & $\mathrm{E}$ & 37.1 & -1.00 & 2.00 & 180 & -1.00 & 2.00 & 180 & $\mathbf{M}$ \\
\hline $\mathrm{NC}$ & 7.8 & -1.75 & 2.00 & 90 & -1.75 & 2.00 & 90 & M & 30.6 & +0.50 & 0.75 & 90 & +0.50 & 0.50 & 90 & $\mathrm{E}$ \\
\hline AW & 5.7 & -2.25 & 2.50 & 90 & -2.25 & 2.00 & 90 & M & 26.9 & +1.50 & 0.00 & & +1.25 & 0.00 & & $\mathrm{E}$ \\
\hline JP2 & 1.9 & -3.75 & 0.00 & & -2.75 & 2.00 & 90 & M & 27.7 & +3.00 & 0.00 & & +3.00 & 0.50 & 90 & $\mathrm{H}$ \\
\hline
\end{tabular}

Astigmatic errors are in plus cylinder form. Age is expressed in months, refractive errors in diopters, and axis data in degrees. Data in bold indicate the eyes used in the data analysis. Rsph, right eye sphere; Rcyl, right eye cylinder; Raxis, right eye axis; Lsph, left eye sphere; Lcyl, left eye cylinder; Laxis, left eye axis; H, hypermetropia; E, emmetropia; M, myopia.

* Children in whom strabismus developed.

increased between the first and last visits and/or showed a significant change as just defined are shown in Figure 1 with filled symbols. This applied to six children who showed increasing hypermetropia and two children who showed increasing myopia. Also shown with filled symbols are data for one child whose refraction remained stable and significantly hypermetropic. Data for eight children whose refractive error remained within the emmetropic range are shown with open symbols. Only one child had a significant refractive error at the first visit (+3.25 D), which reduced to emmetropia (+1.00 D) by the age of 36 months. Data for this child are also shown with open symbols.

Thus, Figure 1 clearly demonstrates why, although there was no change in mean refraction across the group, the variance increased. In some children, hypermetropia increased, in one child it decreased, and in two myopia developed. Thus, in 9 (50\%) of 18 children, emmetropization did not occur; instead, 8 of these 9 children showed an increase in refractive error during the first 3 years of life.

Progression of refractive error was examined individually in each of the 55 children in the study, divided into an infant group $(n=31)$ and an older group $(n=24)$. The infant group included those children whose data are presented in Figure 1. All but four of the infants were seen at age $30 \pm 3$ months, and in these 27 infants, refractive error at the first visit ranged from +6.75 to $-3.75 \mathrm{D}$ (mean error $+1.79 \pm 2.29[\mathrm{SD}])$. By the later age (mean age, $29.6 \pm 1.72$ months), refractive errors ranged from +8.50 to $-5.00 \mathrm{D}$ (mean error, $+2.33 \pm 2.61$ ).
Refractive errors in the infant group at first and last visits are presented in Table 1 . The time elapsed between the first and last visits ranged from 11 to 47 months. The eye used for analysis is indicated in bold and italics: the left eye in 3 children, otherwise the right eye. Those children in whom strabismus developed at some time during the study are indicated with an asterisk. Data for the infant group are presented graphically in Figures 2, 3, and 4, using the most ametropic meridian of one eye. In line with Haugen et al. ${ }^{24}$ the infants were divided by the differing pattern of development of refractive error. Once again, a change in refractive error was defined as a difference of more than $0.75 \mathrm{D}$ between the first and last visits. Figure 2 shows those children whose refractive error increased in a positive direction (those with developing hypermetropia or showing an increase in hypermetropia, $n=13$ ). Figure 3 shows those children in whom refractive error decreased in a negative direction (including increasing myopia; $n=6$ ), and Figure 4 shows 12 children with stable refractive error. In all three figures, children in whom strabismus developed during the course of the study are shown with filled symbols and those with no strabismus with open symbols.

In the increasing group (Fig. 2), 11 of the 13 children had significant hypermetropia at the last visit. In the decreasing group (Fig. 3), one child maintained significant hypermetropia and three progressed to significant myopia. In the stable group (Fig. 4), one child continued to have significant hypermetropia.

Overall, 20 (64.5\%) of the 31 infants had emmetropia at the first visit, and 11 of these children maintained emmetropia. In 


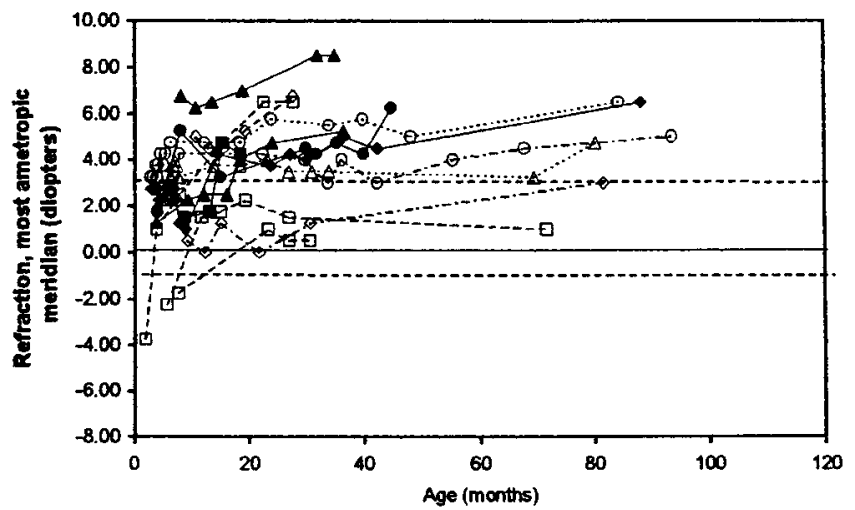

FIGURE 2. Longitudinal progression of refractive error in each child for whom data were available from less than 12 months of age and who showed a positive change in refractive error of more than $0.75 \mathrm{D}$. Filled symbols: those children who had strabismus at some stage. Horizontal dashed lines: limits of emmetropia.

the others, significant refractive errors developed. By the last visit, only 14 (45\%) of the children were emmetropes. Thus, emmetropization occurred in only three children-that is, they had a significant refractive error at the first visit, and their refraction became emmetropic by the last visit.

Among the 31 infants, 10 (32.3\%) had strabismus: 5 of the increasing group (all with significant hypermetropia at the last visit), 2 of the decreasing group (one emmetrope and one myope at the last visit), and 3 of the stable group ( $2 \mathrm{em}-$ metropes and 1 myope at the last visit). There was no significant association between strabismus and refractive error grouping (increasing, decreasing, or stable, $\chi^{2}=1.235, P=$ 0.539 ), nor with refraction at the last visit (hypermetropia, emmetropia, or myopia, $\left.\chi^{2}=3.492, P=0.175\right)$.

Among the 24 older children (who were aged 12-24 months at the first visit), 16 were examined at $48 \pm 10$ months of age. Refractive error for these 16 children ranged, at the first visit, from +7.00 to $-3.25 \mathrm{D}$ (mean error, $+3.02 \pm 2.99$ ). At the later visit (mean age, $47.1 \pm 6.2$ months), refractive error ranged from +8.75 to $-2.00 \mathrm{D}$ (mean error, $+3.30 \pm 3.29$ ).

Refractive errors in all children in the older group at first and last visits are presented in Table 2 . One of the children (SW) was uncooperative for refraction of the left eye at the first visit. Data for the right eye are included, because the examiner was confident in results for this eye, and there was no strabis-

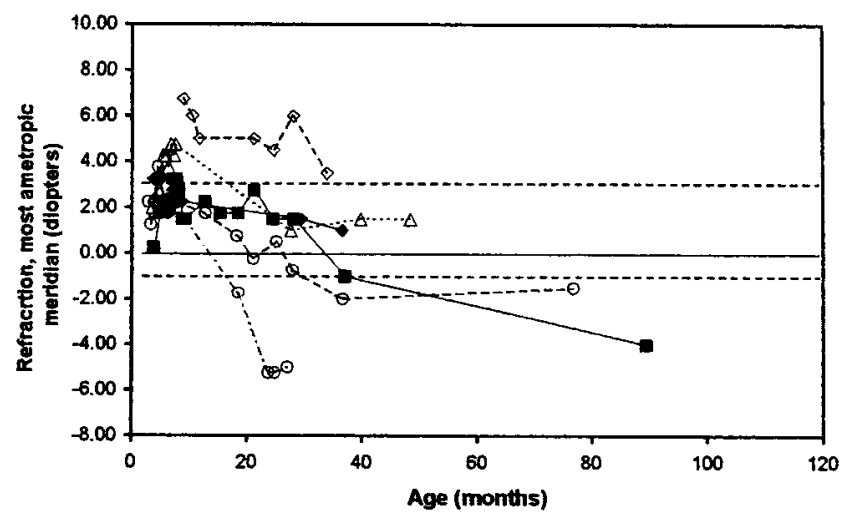

FIGURE 3. Longitudinal progression of refractive error in each child for whom data were available from less than 12 months of age and who showed a negative change in refractive error of more than $0.75 \mathrm{D}$. Filled symbols: those children who had strabismus at some stage. Horizontal dashed lines: limits of emmetropia.

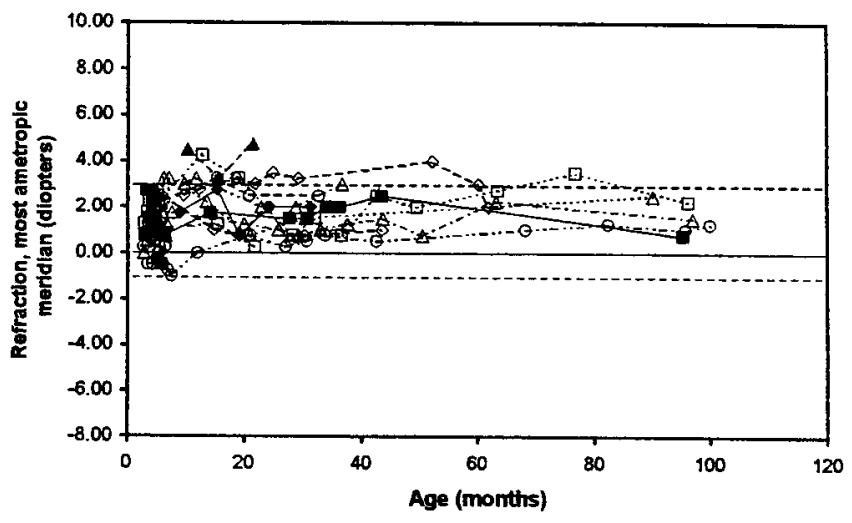

FIGURE 4. Longitudinal progression of refractive error for each child for whom data were available from below the age of 12 months and who showed no significant change in refractive error. Filled symbols: those children who had strabismus at some stage. Horizontal dashed lines: limits of emmetropia.

mus. Graphic data are shown in Figure 5, again with strabismus indicated by filled symbols. Nine children remained or became hypermetropic and two remained myopic. At the first visit, 11 children had emmetropic refraction; by the last visit, 9 of the 24 children did.

Six children had strabismus at the first visit or had strabismus develop during the study. Four had significant hypermetropia throughout, one showed emmetropia and one myopia at the later visits.

\section{Astigmatism and Anisometropia}

As Table 1 shows, only eight of the infant group had significant astigmatism at the first visit. The highest value was $2.50 \mathrm{D}$ (mean astigmatism across all infants, $0.58 \pm 0.78 \mathrm{D}$ ). All but one of these infants had no significant astigmatism by the last visit. The remaining child had reduced cylinder from 2.00 to 1.00 by 30 months of age. In three infants who had no significant astigmatism at the first visit, astigmatism of 2.00, 1.50, and $1.00 \mathrm{D}$ developed by 3 years of age. Thus, at the last visit, only four children had significant astigmatism (mean astigmatism across all children, $0.36 \pm 0.39 \mathrm{D})$.

Seven of the older children group had significant astigmatism at the first visit (Table 2) with the highest being $2.00 \mathrm{D}$ (mean astigmatism, $0.58 \pm 0.59$ ). Four children retained astigmatism at later visits, and the other three had no significant astigmatism at later visits. In four other children, astigmatism of 1.00 to $2.00 \mathrm{D}$ developed during the course of the study. Of the 12 children in both age groups with significant astigmatism by the last visit, 6 had oblique axes, in eight eyes. All but one eye showed axes consistent with the observations of Haugen et al. ${ }^{24}$ One child (JM in Table 2 ) had a positive cylinder axis in the right eye at 110 (i.e., a negative cylinder axis at the $45^{\circ}$ meridian).

Only two infants (DS and JP2) had anisometropia ( $\geq 1.50 \mathrm{D}$ ) at the first visit. By the last visit, no infants had significant anisometropia. No older children had significant anisometropia at the first visit. In one child (without strabismus), anisometropia of $2.00 \mathrm{D}$ developed by the age of 48 months and but had resolved on subsequent visits. Using the definition of anisometropia of Haugen et al. ${ }^{24}(>1.00$ in spherical power or $>1.50$ in cylinder) and examining all 54 children for whom data were available for both eyes at first and last visits, we found 2 (3.7\%) children with anisometropia at the first visit, and 1 (1.9\%) child with it at the last visit. 
Table 2. Refractive Error Data and Refractive Error Grouping of the Children with Down Syndrome Who Were First Examined between the Ages of 12 and 24 Months

$\begin{array}{lll}\text { First Visit } & \text { Last Visit }\end{array}$

\begin{tabular}{|c|c|c|c|c|c|c|c|c|c|c|c|c|c|c|c|c|}
\hline Child & Age & Rsph & Rcyl & Raxis & Lsph & Lcyl & Laxis & Group & Age & Rsph & Rcyl & Raxis & Lsph & Lcyl & Laxis & Group \\
\hline MJ & 15.5 & +6.00 & 1.00 & 90 & +6.00 & 0.50 & 90 & $\mathrm{H}$ & 48.0 & +6.50 & 2.25 & 80 & +6.50 & 2.25 & 100 & $\mathrm{H}$ \\
\hline $\mathrm{GF}^{*}$ & 18.2 & +6.50 & 0.00 & & +6.50 & 0.00 & & $\mathrm{H}$ & 61.0 & +6.75 & 0.50 & 90 & +6.75 & 0.50 & 90 & $\mathrm{H}$ \\
\hline PW & 12.0 & +5.75 & 0.00 & & +5.75 & 0.00 & & $\mathrm{H}$ & 24.4 & +6.00 & 0.00 & & +6.00 & 0.00 & & $\mathrm{H}$ \\
\hline $\mathrm{JM}$ & 13.6 & +4.00 & 1.50 & 90 & +4.00 & 1.50 & 90 & $\mathrm{H}$ & 38.8 & +6.25 & 0.75 & 110 & +6.25 & 0.75 & 100 & $\mathrm{H}$ \\
\hline $\mathrm{CB}^{*}$ & 16.3 & +4.00 & 0.50 & 5 & +5.00 & 0.00 & & $\mathrm{H}$ & 54.1 & +4.00 & 0.00 & & +4.00 & 0.00 & & $\mathrm{H}$ \\
\hline $\mathrm{TL}^{*}$ & 22.3 & +4.50 & 0.00 & & +4.50 & 0.00 & & $\mathrm{H}$ & 60.6 & +5.00 & 2.00 & 90 & +5.00 & 2.00 & 115 & $\mathrm{H}$ \\
\hline LM & 20.0 & +3.50 & 0.50 & 90 & +3.50 & 1.00 & 90 & $\mathrm{H}$ & 61.1 & +1.00 & 1.00 & 80 & +0.50 & 1.00 & 110 & $\mathrm{E}$ \\
\hline $\mathrm{CE}^{*}$ & 13.5 & +3.00 & 0.00 & & +3.00 & 0.00 & & $\mathrm{H}$ & 49.5 & +4.00 & 0.00 & & +4.00 & 0.50 & 100 & $\mathrm{H}$ \\
\hline $\mathrm{AK}$ & 15.5 & +2.00 & 1.00 & 80 & +1.50 & 1.00 & 130 & $\mathrm{H}$ & 27.1 & +1.50 & 1.00 & 90 & +1.50 & 1.00 & 90 & $\mathrm{E}$ \\
\hline $\mathrm{TP}$ & 14.5 & +2.25 & 0.50 & 90 & +2.25 & 0.50 & 90 & E & 31.4 & +2.00 & 0.00 & & +2.00 & 0.00 & & E \\
\hline DC & 13.0 & +1.75 & 0.50 & 90 & +1.75 & 0.50 & 90 & E & 21.2 & +1.25 & 0.50 & 90 & +1.25 & 0.50 & 90 & $\mathrm{E}$ \\
\hline ED & 21.5 & +2.00 & 0.00 & & +2.00 & 0.00 & & E & 35.9 & +3.50 & 0.00 & & +3.50 & 0.00 & & $\mathrm{H}$ \\
\hline $\mathrm{MC}^{*}$ & 15.4 & +0.25 & 1.50 & 50 & +0.75 & 1.50 & 110 & $\mathrm{E}$ & 57.9 & +0.25 & 1.50 & 60 & -0.25 & 1.25 & 120 & $\mathrm{E}$ \\
\hline $\mathrm{JR}$ & 15.4 & +0.75 & 0.75 & 100 & +0.75 & 0.50 & 105 & $\mathrm{E}$ & 27.3 & +0.50 & 0.00 & & +0.50 & 0.50 & 80 & E \\
\hline $\mathrm{AP}$ & 19.0 & +1.00 & 0.50 & 90 & +1.00 & 0.50 & 90 & $\mathrm{E}$ & 52.2 & -0.25 & 1.75 & 85 & -0.25 & 1.50 & 95 & E \\
\hline RD & 22.0 & +1.25 & 0.00 & & +1.75 & 0.00 & & E & 60.7 & +1.00 & 0.50 & 90 & +1.00 & 0.50 & 90 & E \\
\hline $\mathrm{AH}$ & 15.6 & +1.00 & 0.25 & 90 & +1.00 & 0.00 & & $\mathrm{E}$ & 23.7 & +1.00 & 0.00 & & +1.00 & 0.00 & & E \\
\hline SW & 12.3 & -0.25 & 1.50 & 110 & & & & $\mathrm{E}$ & 18.5 & +0.25 & 0.00 & & +0.25 & 0.00 & & E \\
\hline $\mathrm{CN}$ & 13.3 & +0.50 & 0.50 & 90 & +0.50 & 0.00 & & E & 30.7 & +1.50 & 0.00 & & +1.50 & 0.00 & & E \\
\hline SG & 15.8 & +0.25 & 0.50 & 90 & +0.25 & 0.75 & 90 & $\mathrm{E}$ & 55.0 & +2.00 & 0.50 & 90 & +2.75 & 0.00 & & $\mathrm{E}$ \\
\hline $\mathrm{RC}^{*}$ & 20.0 & -1.00 & 1.00 & 90 & 0.00 & 0.50 & 90 & M & 39.4 & -1.00 & 1.00 & 90 & -1.00 & 1.00 & 90 & M \\
\hline $\mathrm{BB}$ & 14.9 & -1.25 & 2.00 & 90 & -1.25 & 2.00 & 90 & M & 28.0 & +1.50 & 0.00 & & +1.50 & 0.00 & & $\mathrm{E}$ \\
\hline $\mathrm{BP}$ & 15.0 & -1.50 & 0.50 & 90 & -1.00 & 0.00 & & M & 35.8 & -2.00 & 0.00 & & -2.00 & 0.00 & & M \\
\hline $\mathrm{CM}$ & 20.7 & -3.25 & 0.00 & & -3.25 & 0.00 & & M & 42.8 & -2.00 & 1.00 & 75 & -2.50 & 0.50 & 100 & M \\
\hline
\end{tabular}

Data are as expressed and abbreviations as defined in Table 1.

\section{Rate of Change of Refractive Error}

In the infant group, rate of the change in refractive error over the first 30 months in the 27 infants examined at $30 \pm 3$ months was calculated as:

$$
\frac{\text { initial error at first visit }- \text { error at ' } 30 \text { month visit' }}{\text { age at ' } 30 \text { month visit' }- \text { age at first visit }}
$$

Because the expected change in normally developing children is a reduction of refractive error, a change in the appropriate direction (i.e., toward emmetropia, a negative change in hypermetropia, and a positive change in myopia) was designated a negative change. A change in the inappropriate direction (i.e., away from emmetropia) was designated a positive change. Rate of change varied from -0.36 to $0.1 \mathrm{D}$ per month.

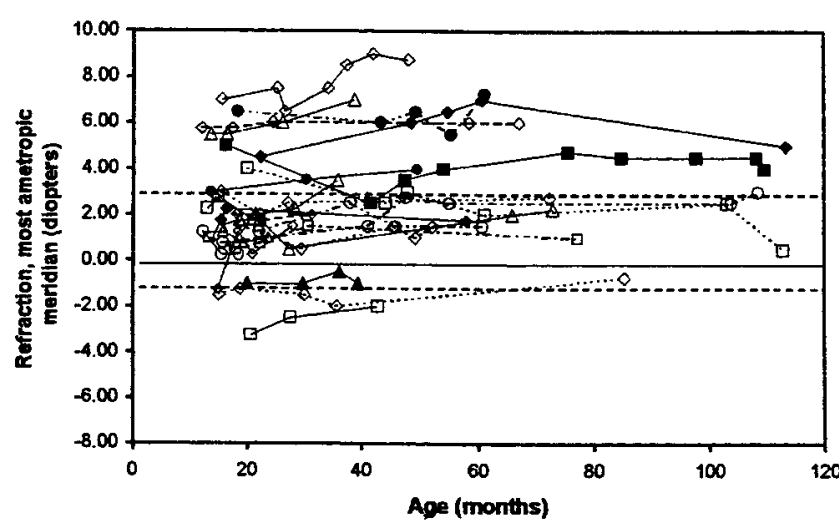

FIGURE 5. Longitudinal progression of refractive error for each child first assessed between the ages of 12 and 24 months. Filled symbols: those children who had strabismus at some stage. Horizontal dashed lines: limits of emmetropia.
The rate of change was plotted against the absolute value of the refractive error at the first visit (Fig. 6). Children who had a negative refraction at the first visit are shown with square symbols, the remaining children with circular symbols. There was no correlation between the rate of change and the initial refractive error $\left(R^{2}<0.001, P=0.938\right)$. Data for two children are indicated with filled symbols. One child had myopia of -3.75 at the first visit and hypermetropia of +3.00 by 30 months, the other had an error of +1.50 (i.e., within the emmetropic range) at the first visit and myopia of $-5.00 \mathrm{D}$ at 30 months. Thus, both children are designated as having a change in the appropriate direction, although both children

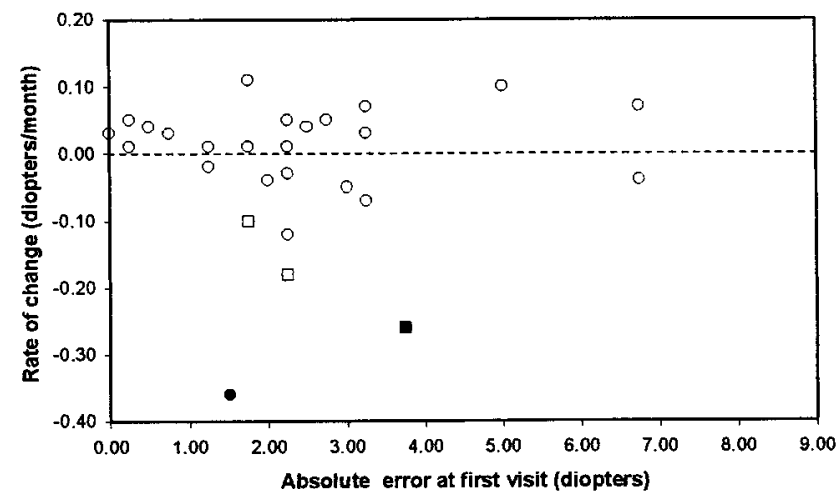

Figure 6. The relationship between the refractive error at the first assessment (2-11 months) expressed in absolute terms and the rate of change of refractive error between first assessment and $30 \pm 3$ months. A negative value for rate indicates a refraction change toward emmetropia, and a positive value indicates a change away from emmetropia. Squares: a myopic refraction at the first visit; circles: a hypermetropic or emmetropic refraction. Filled symbols: the two children whose refraction changed from myopia to hypermetropia in one case and emmetropia to myopia in the other. 


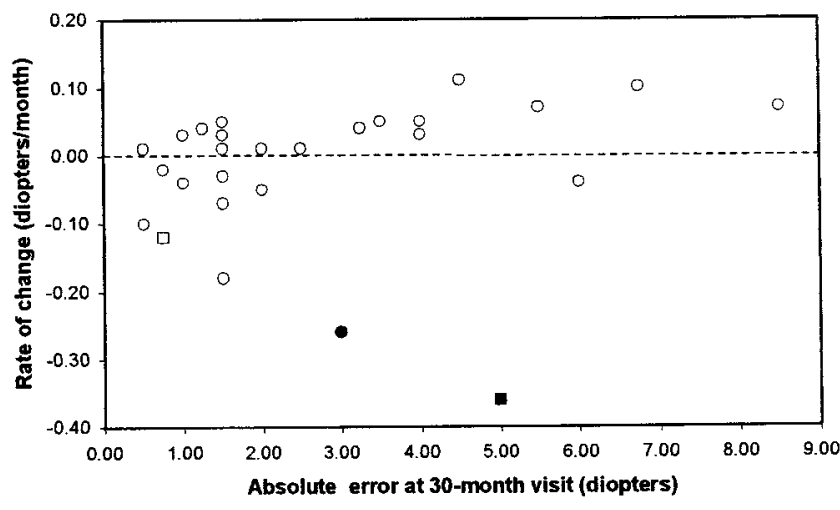

Figure 7. The relationship between the refractive error at $30 \pm 3$ months expressed in absolute terms and the rate of change of refractive error between first assessment and $30 \pm 3$ months. A negative rate of change indicates a refraction change toward emmetropia, and a positive rate indicates a change away from emmetropia. Squares: a myopic refraction at the 30-month visit; circles: a hypermetropic or emmetropic refraction. Filled symbols: the two children whose refraction changed from myopia to hypermetropia in one case and emmetropia to myopia in the other.

had a significant refractive error. When these children were excluded from the analysis, the correlation remained nonsignificant $\left(R^{2}=0.01, P=0.859\right)$.

Figure 7 shows the rate of change plotted against the refractive error at $30 \pm 3$ months, again using absolute refractive error and indicating with square symbols those children who had myopia at 30 months. There was no correlation between the rate of change and the later refractive error when all children were included $\left(R^{2}=0.039, P=0.326\right)$. When the two children whose refractive error changed sign (filled symbols) were excluded, there was a significant correlation between the rate of change of error and the error at 30 months $\left(R^{2}=0.311, P=0.004\right)$. However, the relationship was positive (slope $=0.0177$ ). The greater the refractive error at 30 months, the higher the rate of change in refraction in the inappropriate direction (i.e., away from emmetropia). Overall, in 16 of the 27 children, refractive error changed in the inappropriate direction (in 9 by $0.75 \mathrm{D}$ or less), in 9 children refraction changed toward emmetropia ( 3 by $0.75 \mathrm{D}$ or less), and 2 children, as described earlier, refractive status reversed.

\section{Refractive Error and Strabismus}

The relationship between strabismus and refractive error was assessed in cross-sectional data available for 41 children (from both infant and children groups) who were examined at age $30 \pm 6$ months. Data for refractive error are shown in Figure 8, with $\times$ indicating the children who had strabismus by this age. One child went on to strabismus after this age-she had hypermetropia of $+3.50 \mathrm{D}$ at 30 months. Strabismus was present in 1 of the 5 myopes, 4 of the 22 emmetropes, and 5 of the 14 hypermetropes. Taking both hypermetropia and myopia as a refractive error, there was no significant difference in the prevalence of strabismus among the children with and without a refractive error $\left(\chi^{2}=1.392, P=0.238\right)$. None of the children with strabismus had surgery for squint, either before or during the study.

When the rate of change data for the 27 infants examined before 12 months and at 30 months (of whom 7 had strabismus) were used, there was no significant difference in the rate of change of refractive error between the children with and without strabismus $(t=1.684, P=0.105)$.

Of the total group of 55 children, strabismus (all esotropia) developed in 16 (29.1\%). Four of these children had alternating strabismus, and those remaining had a preferred fixing eye. There was no significant difference in the amount of astigmatism or anisometropia at the first visit between the children with and without strabismus $(t=0.532,1.538, P=0.597$, 0.221 for astigmatism and anisometropia, respectively).

\section{Discussion}

Normally developing children become more emmetropic with age. ${ }^{1,2,4,6-13,19,33,36}$ By contrast, in the present study, refractive errors in Down syndrome often increased with age. There were fewer children whose refractive errors fell within the emmetropic range at later ages (refractive errors in our cohort range from -5.00 to +8.50 DS at 30 months of age). Our data confirm the findings of Haugen et al. ${ }^{24}$ that emmetropization happens in only a minority of children with Down syndrome; in most, significant refractive errors are maintained or develop.

Ehrlich et al. ${ }^{4}$ presented longitudinal data on refractive errors of 254 normally developing infants without anisometropia. Because of their recruitment protocol, their study group included more children with hypermetropia than would be expected in a randomly selected group. At 9 months of age, 96 infants had hypermetropia of $+3.00 \mathrm{D}$ or greater, of whom $39 \%$ retained the error by 20 months. In our infant group, seven children had hypermetropia (and no anisometropia) at the first visit, of whom six (86\%) retained the error.

In our infant group, most of the children with emmetropic refraction at the later visits had simply retained emmetropia from the first visit. Of the 11 infants who had a significant refractive error at the first visit, only 3 (27\%) showed emmetropization and of the 20 infants with emmetropic refraction at the first visit, $9(45 \%)$ went on to have significant refractive errors.

In this study we used a broad range of refraction to define emmetropia (between -0.75 and +2.75 D). Gwiazda et al. ${ }^{9}$ used a much narrower range to define emmetropia: spherical equivalent of 0.00 to $+0.49 \mathrm{D}$, and in their study of 72 normally developing infants aged 0 to 3 months, reported that $22 \%$ had emmetropic refraction. By 6 years, $80 \%$ of their subjects were emmetropes. Among our infants, four (13\%) children fell into this narrow range of emmetropia at the first visit, but by the last visit only two children (6.5\%) were emmetropes. The last visit for our group was much earlier than the 6 years of the subjects in Gwiazda et al. It may be that the emmetropization process is delayed. However, Haugen et al. ${ }^{24}$ presented refraction data at much later ages than for our study, with no evidence of later emmetropization.

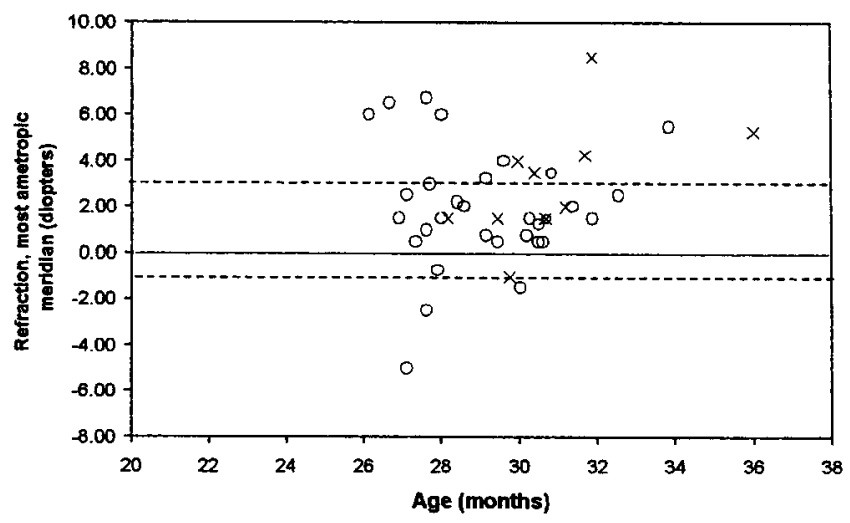

FiguRE 8. Refractive error in 41 children examined at age $30 \pm 6$ months. $(X)$ children who had strabismus; $(\bigcirc)$ children with no strabismus. 
According to Wesson and Maino, ${ }^{21}$ the mean refractive error for a group of children with Down syndrome does not change. This is in contrast, of course, with the overall decrease in refractive error in normally developing children. ${ }^{37}$ The longitudinal data in the current study offer an explanation for this mean effect. Although some children showed an increase in hypermetropia, others showed a negative shift in spherical power to emmetropia and even myopia, and thus the mean remained constant. The variance or range of refractive errors increased with age.

In normally developing children the higher the hypermetropia during the first 6 months, the greater the rate of change of refraction in the following 12 months., ${ }^{2,5}$ The direction of change is negative-that is, the refractive error decreases toward emmetropia. We analyzed the rate of change of refraction (between 3 and 11 months and 30 months) in 27 children with Down syndrome. The findings in normally developing children were not replicated in children with Down syndrome. The rate of change was not related to the initial value, but to the later refractive error. That is, the greater the refractive error at the age of 30 months, the faster the rate of change. Moreover, the rate of change was positive-that is, there was a tendency for refractive errors to progress away from emmetropia. Children with Down syndrome are not always born with higher refractive errors; rather, there is a tendency for the eyes to become increasingly ametropic with age.

Our data, using a noncycloplegic refraction technique, confirm the findings of Haugen et al., ${ }^{24}$ who also showed a high proportion of children with Down syndrome in whom emmetropization did not occur. However, our findings differ in the prevalence of astigmatism. Haugen et al. reported that $57 \%$ of their group had astigmatism $(\geq 1.00 \mathrm{D})$ in one or both eyes at the last visit (age range, 29-132 months). In our study, only $12(21.8 \%)$ of all 55 children had astigmatism by the last visit (age range, 18.5-61.1 months). Haugen et al. also reported a prevalence of anisometropia that was higher than ours (10\% vs. $3.7 \%$ ). Whether the differences in findings can be attributed to a separate demographic cohort, to the younger age range of our cohort, or to the difference in refractive techniques cannot yet be determined.

There was a high prevalence of strabismus among children with Down syndrome: $29 \%$ in our study group at age 30 months. This is in agreement with previous reports. ${ }^{19,38}$ In normally developing children, strabismus is associated with hypermetropia. ${ }^{10,15-18}$ The classic assumption has always been that normally developing children with high hypermetropia overaccommodate to obtain a clear image. This excessive accommodation results in a high degree of accommodative-convergence and is believed to cause esotropia. However, this hypothesis does not explain the findings in children with Down syndrome. The high prevalence of strabismus in children with Down syndrome cannot be attributed to the presence of hypermetropia. The sign or magnitude of the refractive error appears irrelevant. Our data show no association between refraction and strabismus in children with Down syndrome. Neither is the rate of change of refractive error associated with the defect. Haugen and Hovding ${ }^{38}$ also reported strabismus in all refractive groups among their cohort of children with Down syndrome, with an overall prevalence of $42 \%$. Their higher prevalence of strabismus may be explained by the older age of the cohort at the last visit (mean 76 months), when prevalence was determined.

Ingram et al. ${ }^{39}$ have recently disputed the classic theory of strabismus. They have shown that normally developing children with strabismus fail to show a decrease in refractive error and suggested that children with strabismus are destined not to undergo emmetropization and have poor appreciation of blur. This may also be the case in Down syndrome.

Anisometropia was rare in our cohort, which is perhaps surprising considering the high proportion of children with strabismus in the group. Abrahamsson et al. ${ }^{18}$ studied normally developing children between the ages of 1 and 6 years in whom strabismus subsequently developed. Thirteen of the 14 esotropes in the study had anisometropia develop after the onset of strabismus. Increasing hypermetropia in the deviating eye before and after onset of esotropia was observed in 50\% of cases, whereas the expected decrease in hypermetropia was noted in the fixing eye. It was this phenomenon that led to anisometropia. In the current study, refraction often increased in the fixing eye in children with Down syndrome (only the fixing eye data were used in the analyses), and anisometropia was uncommon. Thus, the etiology of strabismus and its dependence and impact on refractive error may be quite different in children with Down syndrome.

In summary, our data have shown that failure of emmetropization to occur is a characteristic of many children with Down syndrome. Children with Down syndrome who have a refractive error in the early months of life are much more likely to maintain or increase the refractive error than to outgrow it. Even children who are emmetropic in the early months are at risk of development of a refractive error. Strabismus is prevalent, whatever the sign or progress of the refractive error. Screening protocols for normally developing children are clearly not applicable to children with Down syndrome. Children with Down syndrome should be monitored for the onset of significant refractive errors and for strabismus regularly throughout early childhood.

\section{Acknowledgments}

The authors thank all the children and parents who have taken and continue to take part in our study, Mike Creasy of the Cytogenetics Department, University Hospital of Wales, for contributing to the recruitment of subjects, and Prema Sastry for acting as liaison with the children's pediatricians.

\section{References}

1. Gordon RA, Donzis PB. Refractive development of the human eye. Arch Opbthalmol. 1985;103:785-789.

2. Saunders KJ, Woodhouse JM, Westall CA. Emmetropisation in human infancy: rate of change is related to initial refractive error. Vision Res. 1995;35:1325-1328.

3. Wood ICJ, Hodi S, Morgan L. Longitudinal change of refractive error in infants during the first year of life. Eye. 1995;9:551-557.

4. Ehrlich DL, Braddick O, Atkinson J, et al. Infant emmetropization: longitudinal changes in refraction components from nine to twenty months of age. Optom Vis Sci. 1997;74:822-843.

5. Atkinson J, Anker S, Bobier W, et al. Normal emmetropization in infants with spectacle correction for hyperopia. Invest Ophthalmol Vis Sci. 2000;41:3726-3731.

6. Hirsch MJ. The changes in refraction between the ages of 5 and 14: theoretical and practical considerations. Am J Optom Arch Am Acad Optom. 1952;29:445-459.

7. Flom MC, Bedell HE. Identifying amblyopia using associated conditions, acuity, and non-acuity features. Am J Optom Physiol Opt. 1985;62:153-160.

8. Garner LF, Yap MKH, Kinnear RF, Frith MJ. Ocular dimensions and refraction in Tibetan children. Optom Vis Sci. 1995;72:266-271.

9. Gwiazda J, Thorn F, Bauer J, Held R. Emmetropization and the progression of manifest refraction in children followed from infancy to puberty. Clin Vis Sci. 1993;8:337-344.

10. Ingram RM, Barr A. Changes in refraction between the ages of one and three and a half years. Br J Ophtbalmol. 1979;63:339-342.

11. Atkinson J, Braddick $O$, French J. Infant astigmatism: its disappearance with age. Vision Res. 1980;40:891-893. 
12. Gwiazda J, Scheiman M, Mohindra I, Held R. Astigmatism in children: changes in axis and amount from birth to six years. Invest Ophthalmol Vis Sci. 1984;25:88-92.

13. Ehrlich DL, Atkinson J, Braddick O, Bobier W, Durden K. Reduction of infant myopia: a longitudinal cycloplegic study. Vision Res. 1995;35:1313-1324.

14. Troilo D. Neonatal eye growth and emmetropisation: a literature review. Eye. 1992;6:154-160.

15. Wildsoet CF. Active emmetropisation: evidence for its existence and ramifications for clinical practice. Opbthalmic Pbysiol Opt. 1997; 17:279-290.

16. Ingram RM, Walker C, Wilson JM, Arnold PE, Dally S. Prediction of amblyopia and squint by means of refraction at age 1 year. $\mathrm{BrJ}$ Opbthalmol. 1986;70:12-15.

17. Ingram RM, Traynar MJ, Walker C, Wilson JM. Screening for refractive errors at age one year: a pilot study. $\mathrm{Br} \mathrm{J}$ Ophthalmol. 1979;63:243-250.

18. Abrahamsson M, Fabian G, Sjostrand J. Refraction changes in children developing convergent or divergent strabismus. BrJ Ophthalmol. 1992;76:723-727.

19. Woodhouse JM, Pakeman VH, Cregg M, et al. Refractive errors in young children with Down syndrome. Optom Vis Sci. 1997;74: 844-851.

20. Pires da Cunha R, Belmiro de Castro Moreira J. Ocular findings in Down's syndrome. Am J Ophthalmol. 1996;122:236-244.

21. Wesson MD, Maino DM. Oculovisual findings in children with Down syndrome, cerebral palsy, and mental retardation without specific etiology. In: Maino DM, ed. Diagnosis and Management of Special Populations. St. Louis: Mosby-Yearbook Inc; 1995:1754.

22. Hestnes A, Sand T, Fostad K. Ocular findings in Down's syndrome. J Ment Defic Res. 1991;35:194-203.

23. Fierson WM. Ophthalmological aspects. In: Van Dyke D, Lang D, Heide F, Van Duyne S, Soucet M, eds. Clinical Perspectives in Down Syndrome. New York: Springer-Verlag; 1990:26-54.

24. Haugen $\mathrm{OH}$, Hovding $\mathrm{G}$, Lundstrom I. Refractive development in children with Down's syndrome: a population based, longitudinal study. Br J Opbthalmol. 2001;85:714-719.

25. Woodhouse JM, Cregg M, Gunter HL, et al. The effect of age, size of target and cognitive factors on accommodative responses of children with Down syndrome. Invest Ophthalmol Vis Sci. 2000; 41:2479-2485
26. Wishart JG. Learning to learn: the difficulties faced by infants and young children with Down's syndrome. In: Fraser WI, eds. Key Issues in Mental Retardation Research. London: Routledge; 1990: 249-261.

27. Mohindra I. A non-cycloplegic refraction technique for infants and young children. J Am Optom Assoc. 1977;48:518-523.

28. Qualley P, Zadnik K, Mutti DO, Friedman NE, Adams AJ. Recruitment of pediatric subjects in a longitudinal-study of refractive error [ARVO Abstract]. Invest Ophthalmol Vis Sci. 1994;35(4):1393. Abstract nr 647.

29. Cruz AAV, Sampaio NMV, Vargas JA. Near retinoscopy in accommodative esotropia. J Pediatr Ophthalmol Strabismus. 1990;27: 245-249.

30. Saunders KJ, Westall CA. Comparison between near retinoscopy and cycloplegic retinoscopy in the refraction of infants and children. Optom Vis Sci. 1992;69:615-622.

31. Chan OYC, Edwards M. Refractive errors in Hong Kong Chinese pre-school children. Optom Vis Sci. 1993;70:501-505.

32. Mohindra I, Held R, Gwiazda J, Brill S. Astigmatism in infants. Science. 1978;202:329-331.

33. Dobson V, Fulton AB, Sebris SL. Cycloplegic refractions of infants and young children: the axis of astigmatism. Invest Ophthalmol Vis Sci. 1984;25:83-87.

34. Abrahamsson M, Fabian G, Andersson AK, Sjostrand J. A longitudinal study of a population based sample of astigmatic children. I. Refraction and amblyopia. Acta Opbthalmol. 1990;68:428-434.

35. Atkinson J, Braddick O. Infant precursors of later visual disorders: correlation or causality. 20th Minnesota Symposium on Child Psychology. 1988;20:35-65.

36. Atkinson J, Braddick O, Robier B, et al. Two infant vision screening programmes: prediction and prevention of strabismus and amblyopia from photo- and videorefractive screening. Eye. 1996;10: $189-198$

37. Saunders KJ. Early refractive development in humans. Surv $O p h$ thalmol. 1995;40:207-216.

38. Haugen $\mathrm{OH}$, Hovding G. Strabismus and binocular function in children with Down syndrome: a population-based, longitudinal study. Acta Opbthalmol Scand. 2001;79:133-139.

39. Ingram RM, Gill LE, Lambert TW. Effect of spectacles on changes of spherical hypermetropia in infants who did, and did not, have strabismus. Br J Ophthalmol. 2000;84:324-326. 